Combining this equation with (4) and (5) we find the free energy of formation of cyanide ion,

$$
\mathrm{C}_{\mathrm{G}}+1 / 2 \mathrm{~N}_{2}+\ominus=\mathrm{CN}^{-} ; \Delta F_{298}^{\circ}=35^{277} \text {. }
$$

Since we take the free energy of formation of hydrogen ion as zero, this equation also gives the free energy of formation of hydrocyanic acid in a solution molal with respect to each ion, namely,

$$
1 / 2 \mathrm{H}_{2}+\mathrm{C}_{\mathrm{G}}+\mathrm{I} / 2 \mathrm{~N}_{2}=\mathrm{H}^{+}+\mathrm{CN}^{-} ; \Delta F_{298}^{\circ}=35277 \text {. }
$$

In order to determine the free energy of undissociated hydrocyanic acid we may use the results of Walker and Cormack ${ }^{1}$ who found from conductance measurements that the dissociation constant at $18^{\circ}$ is $13.2 \times 10^{-10}$. For the heat of dissociation von Steinwehr ${ }^{2}$ found I I Ioo cal. and Thomsen ${ }^{3}$ I0930. Taking I IOOO as the best value we find by means of the van't Hoff equation $\mathrm{K}_{298}=2.06 \times$ Io $^{-9}$. Hence

$$
\mathrm{HCN} \text { (aq.) }=\mathrm{H}^{+}+\mathrm{CN}^{-} ; \Delta F_{298}^{\circ}=11856 \text {. }
$$

Finally, combining Equations 6 and 7 , we have

$$
\mathrm{I} / 2 \mathrm{H}_{2}+\mathrm{C}_{\mathrm{G}}+\mathrm{I} / 2 \mathrm{~N}_{2}=\mathrm{HCN}(\text { aq. }) ; \quad \Delta F_{298}^{\circ}=2342 \mathrm{I} \text {. }
$$

BERREELEY, CAL.

[CONTRIBUTION FROM THE ChEMICAL LABORATORY OF THE UNIVERSITY. OF CALIFORNia.]

\title{
THE SPECIFIC HEATS AT LOW TEMPERATURES OF SODIUM, POTASSIUM, MAGNESIUM AND CALCIUM METALS, AND OF LEAD SULFIDE.
}

By E. D. EASTMAN AND W. H. RODEBUSH.

Received December 28, 1917.

The empirical law of Dulong and Petit, in its original form, states that the heat capacity per gram atom of all the solid elements, excluding those of very low atomic weight, is the same and equal to 6.4 calories per degree. This is the average value of $\mathrm{C}_{p}$, the atomic heat at constant pressure. Lewis ${ }^{4}$ has shown that if $\mathrm{C}_{v}$, the atomic heat at constant volume, be considered, not only are the deviations from the average considerably smaller, but that the new value 5.9 calories per degree is identical with that calculated on the basis of the theory of equipartition. According to this principle the change of kinetic energy with the temperature is $3 R / 2$ per gram atom for any substance whose individual atoms are able to move in every direction. The usual assumption that the atoms of a solid element are in harmonic oscillation about more or less fixed positions requires that they possess potential as well as kinetic energy, and that the time averages of the two be equal. This would give as the atomic heat $3 \mathrm{R}$ or 5.97 calories

${ }^{1}$ Walker and Cormack, J. Chem. Soc., 77, I6 (I900).

${ }^{2}$ Von Steinwehr, $Z$. physik. Chem., 38, I98 (1901).

3 Thomsen, "Thermochemistry," 1908, p. 252.

"Lewis, This Journal, 29, I I65 (1907); Z. anorg. Chem., 55, 200 (1907). 
per degree. The agreement between fact and theory has in the past been regarded as proof of the validity of the equipartition law applied to solids.

Much recent experimental and theoretical research shows however that the principle does not hold under all circumstances. Lewis and Adams ${ }^{1}$ have expressed the belief that the atoms do not in general gain as much energy as required by it, but that the law is a limiting one, more closely approached the higher the temperature, the heavier the atoms, and the weaker the constraints operating upon them. Upon this basis it is evident that the energy gained by the atom in a temperature rise of one degree will depend upon the particular values of these three variables, and that the value $3 \mathrm{R}$ for the atomic heat will be reached as the limit. Whether these assumptions are correct or not, the deductions are in accord with the actual behavior, over very wide ranges of temperature, of the many substances hitherto studied. The Dulong and Petit generalization is possible because at ordinary temperatures, the region of most rapid rise of specific heat has already been passed for most elements, and the limit nearly reached.

While atomic heats smaller than $3 \mathrm{R}$ may be accounted for as above, any instances where $C_{v}$ is found to exceed 6 must be regarded as exceptional and requiring special explanation. Lewis, in the paper referred to, gives 6.4 as the value for sodium, and 6.5 for potassium. Subsequently, Dewar ${ }^{2}$ has reported the value 6.3 as the mean $C_{p}$ of cesium between the boiling points of hydrogen and nitrogen. Though this is the specific heat at constant pressure, it is probable that $\mathrm{C}_{p}-\mathrm{C}_{i}$, even for an element like cesium, is very small at such low temperatures. Also the work reported by Nernst and Schwers $^{3}$ on magnesium showed normal values at the lower temperatures, becoming abnormally high at the upper limit of their investigation. It was suggested to us by Professor G. N. Lewis that the strong electro-positive character of all these metals might be of much significance in connection with their unusually high specific heats, and that a detailed study of the alkali metals would prove of interest. With this object in view. measurements at temperatures between $65^{\circ}$ and $300^{\circ}$ absolute have been made, by methods described below, of the specific heats of sodium, potassium, magnesium and calcium.

In connection with another problem the specific heats of lead sulfide (galena) have also been determined. As the investigation has been interrupted before it could be extended to other substances, it has seemed well to include, without further discussion, the results obtained for it with the tabulations of the data for the metals.

${ }^{1}$ Lewis and Adams, Phys. Rev., 4, 331 (1914).

a Dewar, Proc. Roy. Soc. London, $(A) 89, x_{5} 8$.

${ }^{3}$ Nernst and Schwers, Sitz. Ber Preuss. Akad. Wiss., r, 255 (1914). 


\section{Experimental Methods.}

The Temperature Scale.--Preliminary to the specific heat experiments was the establishment of the temperature scale. As the instrument for the measurement of temperatures, the copper-constantan thermocouple was chosen. It lacks the ease of calibration of the platinum resistance thermometer. Its form, its ease of replacement and the absence of disturbing heating effects are the factors which led to its choice in spite of this. As a standard a four-couple element of No. 30 "Ideal" wire, made by the Electrical Alloy Co., of Morristown, New Jersey, and No. 35 copper wire was used. The homogeneity of the constantan wire was tested by the method of White. ${ }^{1}$

Between the freezing point of mercury and the transition point of sodium sulfate decahydrate the couple had been calibrated by the Bureau of Standards. At lower temperatures comparison was made with nitrogen, oxygen and carbon dioxide vapor-pressure thermometers, as described by von Siemens. ${ }^{2}$ The gases used were purified by his methods. Before the final filling the thermometers were evacuated several times while being heated in all parts to remove gases retained by the glass surfaces. The mercury used in the manometers was washed in $\mathrm{HNO}_{3}$ and distilled in a current of air, being carefully boiled out in the thermometers prior to their filling with gas. The manometers were provided with an improved form of trap for eliminating gases in the closed end. The comparison with the oxygen thermometer was made by placing the condensation tube of the latter by the side of the thermocouple junction in liquid air, both being surrounded by a mantle of sheet copper. The liquid air boiling under atmospheric pressure was found to maintain a sufficiently constant temperature. Pressure and e. $m$. f. readings were made simultaneously. The nitrogen points were obtained with the thermometers imbedded in solid mercury contained in a copper tube immersed in liquid air boiling under reduced pressure. For the carbon dioxide comparison constant-temperature baths of solid $\mathrm{CO}_{2}$ and various organic liquids were available. Potential measurements were made with the potentiometer described in a previous paper. ${ }^{3}$ The height of the mercury columns was read on meter sticks carried between the two arms of the manometers, an accuracy of $\mathrm{I} \mathrm{mm}$. or better being obtained.

From the pressure readings the temperatures were given by the work of von Siemens as recalculated by Holst ${ }^{4}$ on the basis of the latest calibration of the Leiden standard resistance thermometer. Siemens' results in the case of oxygen are in good agreement with those of Kammerlingh-Onnes. ${ }^{5}$

${ }^{1}$ White, This JOURNal, 36, 2292 (1914).

2Von Siemens, Ann. Physik., [4] 42, 87 (1913).

${ }^{3}$ Randall, von Bichowsky and Rodebush, This Journal, 38, I266 (Igi6).

4 Holst, Verslag. Akad. Wetenschappen, 24, 603 (1915).

' Kammerlingh-Onnes, Leiden, Comm. Phys. Lab., I07 (I908). 
The carbon dioxide vapor-pressure curve obtained by him joins on well with that of Henning ${ }^{1}$ in the neighborhood of atmospheric pressure, and with Nernst's ${ }^{2}$ at small pressures. The nitrogen values differ by $0 . I^{\circ}$ to $0.2^{\circ}$ from the older and apparently less accurate ones of Fischer and Alt. ${ }^{3}$ The freezing point of mercury given by Henning is $234.20^{\circ} \mathrm{K}$, on the Leiden scale it is $234.24^{\circ} \mathrm{K}$, and Wilhelm ${ }^{4}$ at the Bureau of Standards finds $234.22^{\circ}$ $\mathrm{K}$; the value adopted for this work is $234.2^{\circ} \mathrm{K}$.

Hitherto, no simple equation expressing the behavior of the copperconstantan thermocouple over a considerable temperature range has been proposed. It was found, however, that an equation of the type

$$
\mathrm{E}=\mathrm{E}_{0}+a \mathrm{~T}^{n},
$$

in which $\mathrm{E}$ and $\mathrm{T}$ represent the e. $\mathrm{m}$. $\mathrm{f}$. and absolute temperature respectively, and $\mathrm{E}_{0}, a$ and $n$ are constants, fitted very closely these experiments. No equation valid over the entire range within the limits of experimental error was found; the simple equation was restricted therefore to the upper temperatures. Below the sublimation point of carbon dioxide, where the variation in thermo-electric power is more rapid, a term involving a fourth constant was introduced, the equation becoming

$$
\mathrm{E}=\mathrm{E}_{0}+a \Gamma^{n}+\mathrm{b} \mathrm{T}^{2} \text {. }
$$

The numerical values of the constants used in Equation I are:

$$
\begin{aligned}
& \mathrm{E}_{\mathrm{o}}=26672, a=-2.2143, n=1.675 . \\
& a=-0.74097, b=-17.45, n=1.837 .
\end{aligned}
$$

\begin{tabular}{|c|c|c|c|c|c|c|}
\hline Standard. & $\mathrm{T}$. & $E_{\text {obs. }}$ & $\begin{array}{l}\text { Ecalc. } \\
\text { Eq. } 2 .\end{array}$ & $\Delta \mathrm{T}$ & $\begin{array}{l}\text { Ecalc. } \\
\text { Eq. } 1 .\end{array}$ & $\Delta \mathrm{T}^{\mathrm{T}}$ \\
\hline \multicolumn{7}{|l|}{$\mathrm{N}_{2}$ thermometer No. I: } \\
\hline$p=135.3 \ldots \ldots \ldots$ & $65 \cdot 32$ & 24093 & 24100 & $-0.1 \mathrm{I}$ & .. & . \\
\hline $\begin{array}{l}p=238.5 \ldots \ldots \ldots \\
\mathrm{N}_{2} \text { thermometer No. } 2:\end{array}$ & 68.80 & 23879 & 23879 & 0.00 & .. & . \\
\hline $\begin{array}{c}p=557.2 \ldots \ldots \ldots \\
\mathrm{O}_{2} \text { thermometer: }\end{array}$ & 74.85 & 23487 & 23480 & to. 10 & $\cdots$ & \\
\hline$p=261.7 \ldots \ldots \ldots$ & 81.05 & 23044 & 23047 & to.oI & 23036 & -1.80 \\
\hline$p=34 \mathrm{I} .2 \ldots \ldots \ldots \ldots$ & $83 \cdot 10$ & $2290 \mathrm{I}$ & 22900 & $\multimap 0.03$ & $\ldots$ & .. \\
\hline $\begin{array}{l}\quad p=458,4 \ldots \ldots \ldots \\
\mathrm{CO}_{2} \text { thermometer: }\end{array}$ & 85.52 & $2272 \mathrm{I}$ & 22723 & -0.03 & $\ldots$ & \\
\hline$p=349.1 \ldots \ldots \ldots$ & 185.5 & 12718 & 12721 & -0.02 & 12717 & to.or \\
\hline$p=520.4 \ldots$ & $190 . \mathrm{I}$ & 12139 & 12139 & 0.00 & 12133 & to.05 \\
\hline $\mathrm{Hg}$ freezing point. & 234.2 & 6052 & 6050 & +0.01 & $606 \mathrm{I}$ & -0.06 \\
\hline $\mathrm{H}_{2} \mathrm{O}$ freezing point $\ldots \ldots \ldots$ & 273.1 & o & -75 & +0.45 & $-I$ & to. 00 \\
\hline $\mathrm{Na}_{2} \mathrm{SO}_{4} \cdot \mathrm{IOH}_{2} \mathrm{O}$ transition & & & & & & \\
\hline point $\ldots \ldots \ldots \ldots \ldots$ & 305.5 & -5509 & .. & . & -5512 & +o.02 \\
\hline
\end{tabular}

TABLE I.-CALIBRATION OF THERMO-ELEMENT. 
The results of the comparison are given in Table I. The first column shows the comparison standards, the pressures being expressed in millimeters of mercury at $0^{\circ} \mathrm{C}$. The second column gives the absolute temperature, and the third observed e. m. fs., in microvolts. Cols. 4 and 6 contain the values calculated for the e. m. fs. by Equations 2 and $\mathrm{I}$, respectively. The columns headed $\Delta \mathrm{T}$ give the differences in degrees between observed and calculated values of the temperature.

The figures in Table I are for the four-couple element. In the actual specific heat measurements single couples were always used, being checked against the standard after runs. From the equations above, a table was constructed giving the electromotive force and its temperature coefficient for a single couple at $10^{\circ}$ intervals between $60^{\circ}$ and $300^{\circ}$ absolute. By its use $\mathrm{T}$ and $d \mathrm{E} / d \mathrm{~T}$ were conveniently determined with an accuracy approaching $0.1^{\circ}$ and $0.5 \%$, respectively.

The Measurement of Specific Heats.-In principle, the method ${ }^{1}$ first used by Eucken and since then further developed in Nernst's laboratory was adopted. By this scheme the temperature rise caused by supplying electrically a measured amount of heat to the substance under investigation is determined at the desired temperatures, the material being suspended in vacuo and protected as well as possible from radiation exchanges with the surroundings.

The magnesium and calcium, in the form of cylindrical blocks were wrapped with No. 36 (B. and S. gauge) silk insulated constantan wire, which formed a heating coil of I Io ohms' resistance. Thermal contact was secured with paraffin or shellac. The leads, four in number, were of No. 40 copper wire. A thermocouple was bound on by means of the heating wire. The block was then enclosed in a sheath of thin sheet copper, highly polished on the outside.

The sodium and potassium were melted in vacno and forced through a small tube into a thin-walled brass container provided with a tightly fitting cover. The inclusion of an appreciable amount of oxide was avoided in this way, and good thermal contact with the container secured. The thermocouple was soldered to the outside of the can, the latter wrapped with constantan wire and covered with copper, as before. The heat capacity of the can with the same fittings had been accurately determined previously.

The container for the lead sulfide was of copper, the thermocouple and heating coil again being on the outside protected by the shield of polished copper foil. Partitions of thin copper extended from the walls to the interior of the container. Small cubes of galena were inserted, the cover carefully soldered on and the can filled with hydrogen through a small copper tube which was then closed. The hydrogen and the copper partitions gave quick and thorough distribution of heat.

1 Nernst and Schwers, Loc. cit. 
Thus prepared, the materials were suspended in the lower end of a tube of pyrex glass, $5 \mathrm{~cm}$. diameter and $60 \mathrm{~cm}$. long. (The calorimeters were approximately $9 \times 4 \mathrm{~cm}$.) The tube was closed at the mouth by another tube of smaller diameter (leading to the vacuum pump) kitted in with deKhotinsky cement, the lead wires passing through this seal. The procedure then was to admit hydrogen to the tube to act as a conductor between the calorimeter and the cooling bath surrounding the tube. When the desired temperature had been reached, the hydrogen was pumped out. When the tube was sufficiently evacuated, as indicated by the character of the discharge produced within it when connected on the outside to the terminal of a spark coil, the measurements were begun, proceeding from lower to the higher temperatures.

The quantity of electrical energy supplied in a determination was known from the current in the coil and the voltage at its terminals, measured on carefully calibrated Weston instruments, the time of heating being measured with a stop-watch. A battery of lead storage cells discharging slowly through a high resistance, from the terminals of which the heating current was taken, gave a sufficiently constant voltage. The change in resistance in the copper leads during heating caused a small variation in the current during runs at low temperatures; this variation, which was seldom as much as $1 \%$, was corrected for by averaging readings taken at suitable intervals. The resistance of the constantan heating coil did not vary appreciably during runs, which is an important advantage.

The prevention, as far as possible, of heat exchange between the calorimeter and its surroundings obviously is very necessary, so that a very high vacuum is required. This was secured by means of a remarkably efficient and satisfactory mercury vapor pump designed in this laboratory by Dr. G. E. Gibson. Radiating surfaces of the calorimeter were of highly polished copper, which is an even better reflector, at low temperatures, than silver. The walls of the containing tube were silvered inside. A series of baffle plates of copper were placed above the calorimeter, which were cupshaped in design, and when in place expanded against the walls of the tube, giving good thermal contact. From the lower baffle, which was a plate supported on a constriction in the tube, the calorimeter was hung by a silk thread. The temperature of the surroundings was maintained approximately equal to that of the calorimeter. Below $100^{\circ} \mathrm{K}$. the effect of radiation is small enough to allow considerable latitude in this, and the liquid air bath surrounding the tube sufficed. Between $100^{\circ} \mathrm{K}$. and the boiling point of carbon dioxide, and at room temperature, a copper tube of large heat capacity was employed. This tube, which fitted closely over the glass-containing tube, was provided with a heating coil and thermocouple, permitting the regulation of its temperature. A little liquid air in the bottom of the long Dewar tube in which it was enclosed kept it 
from warming indefinitely. Usually the mantle was maintained at a temperature such that the calorimeter remained constant in its temperature after heating. When necessary, $i$. $e$, when radiation effects were very large, the mantle and calorimeter could be heated simultaneously. In the lower range it was found that the calorimeter always had a warming rate until it reached a temperature considerably higher than that of the surrounding bath. This temperature difference was found to be reduced by the use of a long Dewar tube, and by looping the lead wires to the bottom of the glass tube and pressing them against the walls of the tube by means of the baffles.

\section{The Experimental Results.}

The results of the measurements thus far made are shown in Tables II-VI. As a typical example of the way in which $\mathrm{C}_{p}$ values there given were obtained, one of the magnesium runs will be described in detail. At 1.49 P.M. the magnesium was heated for $124.4 \mathrm{sec}$., the total energy supplied being calculated to be 44.60 calories. (The current in coil was 0.1196 ampere, the voltage at terminals 12.53 . The value $j=0.239 \mathrm{I}$ $\mathrm{cal}_{.15^{\circ}}$ was used as the electrical equivalent of heat.) The readings of the potentiometer are given at minute intervals before and after heating.

$\begin{array}{rrrl}\text { Time. } & \text { E. M. F. } & \text { Time. } & \text { E. M. F. } \\ 1.47 & 5742.7 & 2.00 & 5690.7 \\ 1.48 & 5742.7 & 2.01 & 5690.8 \\ 1.49 & 5742.7 & 2.02 & 5690.9 \\ 1.58 & 5690.2 & 2.03 & 5690.9 \\ 1.59 & 5690.4 & 2.04 & 5690.9 \\ 2.00 & 5690.7 & 2.05 & 5690.9\end{array}$

The initial and final readings are seen to be 5742.7 and 5690.9 , respectively, the average being $57 \mathrm{I} 7$ and the change $5 \mathrm{I} .8$ microvolts. Interpolation in the table previously mentioned shows $83.5^{\circ} \mathrm{K}$. as the temperature, and r8. 16 microvolts as the value of $d \mathrm{E} / d \mathrm{~T}$, corresponding to an e. $\mathrm{m}$. f. of $57 \mathrm{I} 7$ microvolts. $44.60 \times 18.16 / 51.8=15.64$ cal. is thus the heat capacity of the block of magnesium and its copper sheath. The latter, including $0.6 \mathrm{~g}$. of constantan which was figured as copper, weighed $10.7 \mathrm{~g}$. Its heat capacity at $83.5^{\circ} \mathrm{K}$. was taken from the work of Nernst and Lindemann ${ }^{1}$ to be 0.52 cal., leaving 15.12 cal. as the heat capacity of the I I0.3 g. of magnesium in the block. This gives $\mathrm{C}_{p}=3.33 \mathrm{cal} . / \mathrm{deg}$. as the atomic heat capacity at constant pressure. In the example given the temperature was constant both at the beginning and end of the run. This was very often the case. When there was a cooling or warming rate it was usually very regular and could be corrected for easily without

\footnotetext{
i Nernst and Lindemann, Z. Electrochem.. 17, 818 (1911).
} 
plotting. Corrections were never over three per cent. of the total rise in temperature.

$\mathrm{C}_{p}-\mathrm{C}_{v}$ for sodium, potassium and magnesium has been calculated at $293^{\circ} \mathrm{K}$. by Lewis ${ }^{1}$ from the compressibilities and coefficients of expansion. Values at other temperatures were obtained from the approximate proportionality ${ }^{2}$ of $\mathrm{C}_{p}-\mathrm{C}_{v}$ to $\mathrm{T}^{3 / 2}$. To obtain $\mathrm{C}_{v}$ in the case of calcium, a second approximate relation connecting $\mathrm{C}_{p}, \mathrm{C}_{v}, \tau$ and ${ }^{\top}{ }^{\prime} s$, was used, $\mathrm{T}_{s}$ representing the melting point.

The error of the measurements is thought not to exceed $1 \%$. The sodium and potassium used were Kahlbaum's. Qualitative tests of the magnesium showed only negligible amounts of $\mathrm{Al}, \mathrm{Fe}, \mathrm{SiO}_{2}$. Analysis of the calcium showed $97.75 \% \mathrm{Ca}, 0.85 \% \mathrm{Cl}, \mathrm{x} .08 \%$ of $\mathrm{Fe}$ and $\mathrm{Al}$ as oxides, and a trace of $\mathrm{Mg}$. Very perfect small cubes of galena were selected for the measurements, the presumption being that errors due to impurity in the crystals would not exceed the errors from other sources. The weights of the substances used in the specific heat determinations were $2.396 \mathrm{mols}$ of sodium, I.046 mols of potassium, 4.535 mols of magnesium, $3.55^{\circ}$ mols of calcium, and 1.316 mols of lead sulfide. The heat capacities of the containers and fittings varied between the following indicated percentages at the lowest and highest temperatures in the different cases: Sodium, roI $8 \%$; potassium, $22-34 \%$; magnesium. $3-5 \%$; calcium, $5-7 \%$; lead sulfide $14-20 \%$.

ATOMIC HEAT CAPACITIES.

'TABLE IT.-SODIUM.

$\begin{array}{rccccc}\text { T. } & C_{p .} & C_{v .} & \text { T. } & C_{p .} & C_{b .} \\ 64.6 & 4.52 & 4.47 & 159.0 & 5.99 & 5.79 \\ 67.9 & 4.66 & 4.60 & 181.7 & 6.15 & 5.9 I \\ 71.1 & 4.77 & 4.71 & 183.8 & 6.17 & 5.92 \\ 74.2 & 4.81 & 4.75 & 234.7 & 6.43 & 6.07 \\ 84.6 & 5.08 & 5.00 & 292.1 & 6.78 & 6.28 \\ 94.8 & 5.30 & 5.21 & 293.5 & 6.79 & 6.29 \\ 156.8 & 6.02 & 5.82 & & & \\ & & & & & \\ \text { T. } & C_{p .} & C_{y .} & \text { TABLE III-POTASSIUM. } & & \\ 68.6 & 5.76 & 5.69 & 116.7 & 6.20 & 6.05 \\ 72.3 & 5.74 & 5.67 & 119.3 & 6.23 & 6.07 \\ 76.0 & 5.78 & 5.70 & 152.2 & 6.40 & 6.18 \\ 79.8 & 5.86 & 5.77 & 199.5 & 6.68 & 6.34 \\ 87.0 & 5.96 & 5.86 & 203.5 & 6.72 & 6.37 \\ 94.1 & 6.08 & 5.97 & 285.1 & 7.05 & 6.47 \\ 101.8 & 6.06 & 5.95 & 286.7 & 7.10 & 6.52\end{array}$

'Lewis, This Journal, 29, i 165 (1907).

2 Lindemann and Magnus, Z. Electrochem., 16, 269 (I9ro). 
TABIE IV.-MAGNESIUM.

\begin{tabular}{rccccc}
\multicolumn{1}{c}{ T. } & $C_{p .}$ & $C_{y .}$ & T. & $C_{p .}$ & $C_{v .}$ \\
74.9 & 2.90 & 2.87 & I 55.2 & 5.08 & 5.00 \\
78.3 & 3.03 & 3.00 & I72.4 & 5.31 & 5.22 \\
83.5 & 3.33 & 3.30 & 192.6 & 5.55 & 5.44 \\
92.1 & 3.61 & 3.57 & 220.0 & 5.82 & 5.69 \\
IOI.5 & 3.99 & 3.93 & 237.3 & 5.83 & 5.69 \\
II 4.5 & 4.47 & 4.42 & 253.5 & 5.98 & 5.82 \\
II5.8 & 4.44 & 4.39 & 255.2 & 5.86 & 5.70 \\
I32.7 & 4.77 & 4.71 & 288.5 & 6.11 & 5.91
\end{tabular}

TABLE V.-CaLciUm.

\begin{tabular}{rccccc}
\multicolumn{1}{c}{ T. } & $C_{p .}$ & $C_{v}$. & T. & $C_{p .}$ & $C_{v .}$ \\
67.6 & 3.93 & 3.91 & I 43.3 & 5.68 & 5.59 \\
70.4 & 4.02 & 4.00 & 145.2 & 5.73 & 5.63 \\
73.3 & 4.16 & 4.13 & 163.2 & 5.97 & 5.85 \\
76.2 & 4.28 & 4.25 & 198.5 & 6.36 & 6.20 \\
80.6 & 4.42 & 4.39 & 200.0 & 6.38 & 6.22 \\
92.7 & 4.81 & 4.77 & 230.3 & 6.46 & 6.27 \\
94.9 & 4.92 & 4.87 & 287.2 & 6.74 & 6.48 \\
103.4 & 5.07 & 5.02 & 293.5 & 6.75 & 6.48 \\
I4I.4 & 5.70 & 5.61 & & &
\end{tabular}

TABle VI-Lead Sulfide (Galena).

\begin{tabular}{|c|c|c|c|c|c|c|c|}
\hline T. & $c_{p}$. & $\mathrm{T}$. & $c_{p}$ & T. & $C_{p}$. & T. & $c_{p}$. \\
\hline 63.8 & $7 \cdot 71$ & 90.1 & 9.12 & I $3 x \cdot 3$ & I0. 33 & I 82.3 & I I. I 7 \\
\hline 66.6 & $7 \cdot 96$ & 96.9 & 9.45 & 133.6 & 10.34 & 196.6 & II $.40^{\circ}$ \\
\hline 70.0 & 8.09 & 100.0 & 9.59 & $142 \cdot 3$ & 10.64 & 196.7 & II . 50 \\
\hline 73.1 & 8.34 & $105 \cdot 3$ & 9.68 & $149 . I$ & $10.6 \mathrm{I}$ & 197.6 & II 45 \\
\hline 75.9 & 8.40 & 109.2 & 9.70 & 155.0 & 10.90 & I 98.7 & II $.4^{8}$ \\
\hline 78.8 & 8.63 & I II 8 & 9.84 & $161 \cdot 7$ & I0. 84 & 235.0 & II .80 \\
\hline 81.7 & 8.80 & I I 4.3 & 9.88 & 168.4 & I0. 95 & 237.0 & I1 . 86 \\
\hline 84.6 & 8.88 & 121.9 & 9.98 & 175.3 & I I . 24 & 280.7 & 12.01 \\
\hline 87.4 & 9.07 & 124.2 & IO. IO & 180.0 & II I I 3 & 282.7 & 12.16 \\
\hline
\end{tabular}

\section{Discussion of Results.}

The results of our experiments are represented by the individual points in the accompanying diagrams, where $C_{v}$ is plotted against the common logarithm of the absolute temperature. For a detailed account of the advantages of this method of plotting, and for the full significance of the continuous curves, reference is made to a paper by Lewis and Gibson. ${ }^{1}$ Here it will suffice to state that the form of the curve, which is fully shown in Fig. I, is a general one and that only horizontal displacement is required to make it fit exactly the data for any one of a large class of elements which have been investigated over wide ranges of temperature. The criteria which may generally be used to predict whether or not any element belongs in this group would include the alkali metals in it.

${ }^{1}$ Lewis and Gibson, This Journal, 39, 2554 (I917). 
Our values of $\mathrm{C}_{v}$ for magnesium, as shown in Fig. $\mathrm{x}$, follow the regular curve in the lower range of our experiments, but rise above it at the upper temperatures. ${ }^{1}$ This behavior is typical also of sodium and calcium, as

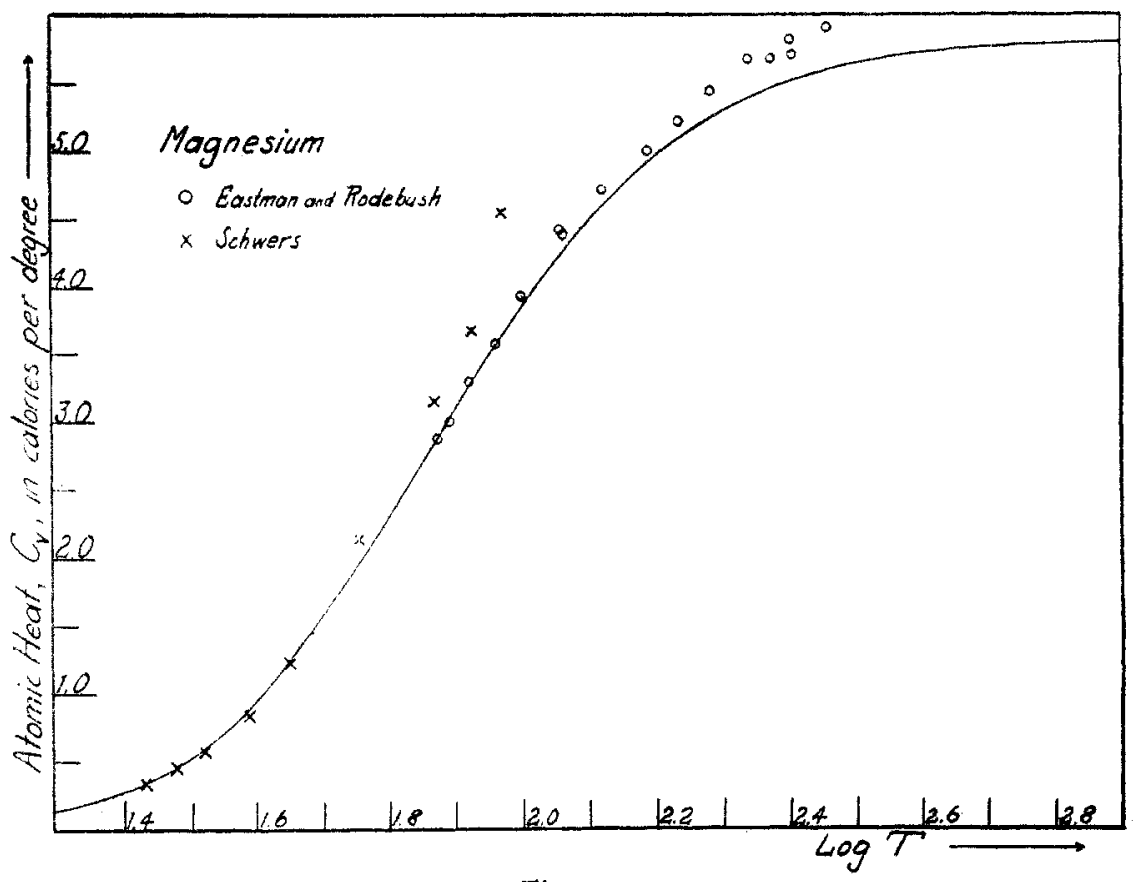

Fig. I.

will be seen from Fig. 2. The points for potassium seem to lie above the regular curve even at the lowest temperatures attained by, us, it being impossible to locate the regular curve corresponding to them by the usual displacement method. The curve may, however, be approximately placed from the measurements of Dewar and the calculations of Lewis and Gibson previously referred to. For purposes of comparison this has been done.

For each metal $C_{v}$ rises well above the normal experimental and theoretical value of 6 . These high specific heats obviously cannot be accounted for solely on the basis of the modified equipartition law mentioned in the introduction to this paper. If the postulate is retained that the oscillations of the atoms are harmonic, ${ }^{2}$ we are led at once to the conclusion that not only the atoms but some at least of their constituent electrons are

${ }^{1}$ It will be noted that our values do not confirm those reported by Nernst and Schwers (Loc. cit.) at liquid air temperatures, but that their points also fall on the regular curve at lower temperatures.

'Langmuir, ThIS JoURnal, 38, 2236 (I916), discusses the possibility that this assumption is not correct in all cases, and points out that if the restoring force does not increase as rapidly as the displacement of the atoms from their equilibrium centers, the 
acquiring thermal energy. If it is granted that the atomic weight and the acting constraints are factors determining the energy absorbed, the electrons should be expected to gain considerable amounts only at comparatively high temperatures. For not only are the electrons by far the lightest of all the atoms, but in most substances they are under large constraints, as indicated by the optical properties. There is much evidence, however, that in metals the electrons are more loosely bound, and that their freedom increases with the electro-positive character of the metal. The temperatures at which their absorption of energy becomes appreciable should be lower therefore, for the alkali metals than for any others, which is in accordance with the behavior we have found.

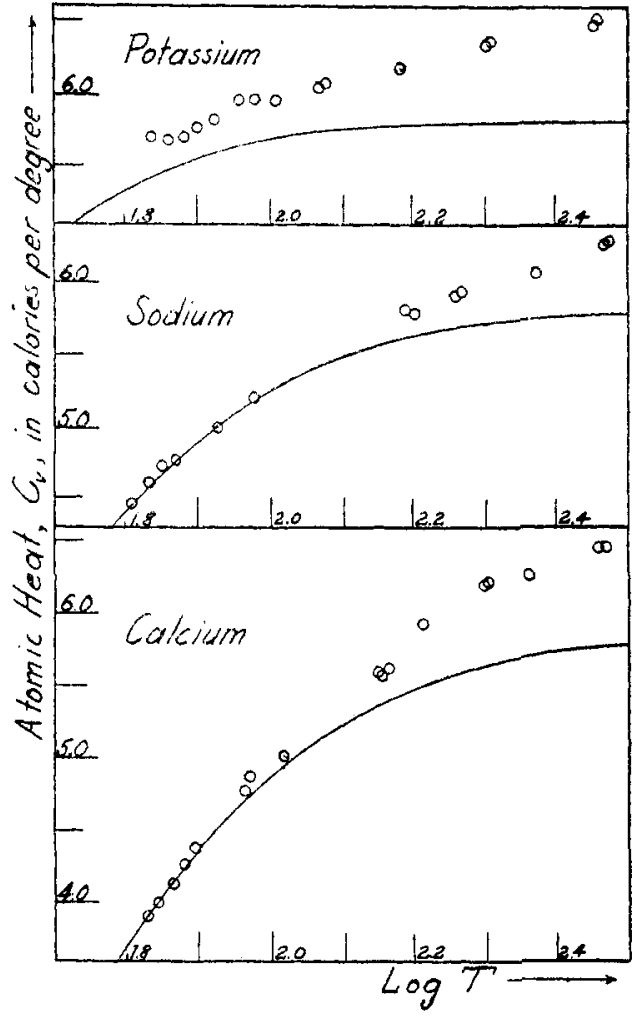

Fig. 2.

Our experiments show further that the deviation from the regular curve at any one temperature is greater for potassium than for sodium and greater for calcium than for magnesium, which presumably is also the order of the freedom of the electrons. We regard these deviations from the normal curve as representing the actual specific heat of the electrons, and believe that the effect will also be shown by the less positive metals, though at higher temperatures. A new and interesting field is thus opened in the comparison of the evidence regarding electronic freedom offered by specific heats, as more extensive data are obtained, with that deduced time average of potential energy may become greater than that of the kinetic energy. As the latter must still be $3 R / 2$, a value of atomic heat greater than $3 R$ would result. At small amplitudes the vibrations of the atoms most probably are harmonic, but with increasing amplitude the conditions mentioned might arise. With metals as far from their melting points as those in this investigation, it seems unlikely that the amplitudes of the atoms should be so large as to destroy the harmonic character of their vibrations. Even if this were the case, there is the possibility that the restoring force would increase more rapidly than the displacement, resulting again in specific heats smaller than 6 . 
from the study of other phenomena, for example, the volta and photoelectric effects.

The writers wish again to acknowledge their indebtedness to Professor G. N. Lewis.

BERRELEY, CAL.

[Contribution from the Geophysical Laboratory, Carnegie Institute of WASHINGTON.]

\title{
THE COLOR OF INORGANIC COMPOUNDS.
}

\author{
By F. RUSSELI V. BICHOWSKY. \\ Received January 10, 1918.
}

In order for a substance to show selective absorption of light in any part of the visible or invisible spectrum it is necessary, according to present electromagnetic theories, that the substance contain some sort of electromagnetic mechanism capable of vibration with a free period corresponding to that of the light absorbed. The mechanism usually assumed is the constrained electron. In other words, substances capable of selective absorption in the visible or ultraviolet are supposed to contain electrons which are held by elastic or pseudo-elastic electrical constraints to some definite point of equilibrium and which are capable of vibration, given a suitable electromagnetic stimulus, with a certain definite free period determined by the magnitude of the constraining forces.

In some cases it is uncertain just what electrons are involved in the absorption. In the case of absorption in the visible and in that part of the ultraviolet extending to say $2100^{\circ} \mathrm{A}$, the overwhelming evidence of organic chemistry showing that color is a function of structure proves that the electrons involved in selective absorption in this region, at least, are the same electrons that take part in chemical union, i.e., are the so-called valence electrons.

Now unfortunately very little is known either about the nature or the magnitude of the forces acting on a valence electron, certainly not enough to justify a quantitative theory of light absorption. However, enough is known about the comparative stability of certain electron arrangements to be able to predict the comparative magnitude of the mean restoring forces acting on valence electrons and thus predict certain qualitative regularities of the absorption spectra of various inorganic compounds. ${ }^{1}$

The magnitude of the mean restoring force acting on a valence electron measures not only the period of mean free vibration of the electron but it

${ }^{1}$ Compared with the vast amount of attention that has been given to the color of organic compounds very little has been given to the more fundamental problem of the color of inorganic compounds. This is probably because it is impossible to make much headway in this field without a ratber definite theory of atom structure. An adequate summary of the earlier work attempting to connect color with valence or atomic weight will be found in Kayser, Handbuch d. Spectroscopie, III, I4I (1905). 